УДК 621.644

\title{
ПЕРСПЕКТИВЫ РАЗВИТИЯ ТЕХНОЛОГИИ И ТЕХНИКИ ГОРИЗОНТАЛЬНО-НАПРАВЛЕННОГО БУРЕНИЯ ПИЛОТНЫХ СКВАЖИН ДЛЯ БЕСТРАНШЕЙНОЙ ПРОКЛАДКИ ТРУБОПРОВОДОВ
}

\section{Саруев Лев Алексеевич',} saruevla@tpu.ru

\author{
Шадрина Анастасия Викторовна', \\ avshadrina@rambler.ru
}

\author{
Саруев Алексей Львович', \\ saruev@tpu.ru
}

\section{Васенин Сергей Сергеевич², vasenin8@gmail.com}

\author{
Пахарев Александр Владимирович³, \\ avpaharev@tpu.ru \\ 1 Национальный исследовательский Томский политехнический университет, \\ Россия, 634050, г. Томск, пр. Ленина, 30. \\ ${ }^{2}$ АО «Газпромнефть - Московский НПЗ», \\ Россия, 109429, г. Москва, Капотня, 2 квартал, 1, корп. 3. \\ ${ }^{3} 000$ «Геотехновация», \\ Россия, 634057, г. Томск, ул. 79-й Гвардейской дивизии, 4/5.
}

Актуальность. В процессе реализации технологии горизонтально-направленного бурения скважин нередко возникают проблемы, связанные с необходимостью преодоления включений или горных пород высокой твердости, что требует использования рационального способа разрушения их ударом. Однако существующие ударные механизмы современных буровых установок формируют силовые импульсы нерациональной формы, не учитывающей свойства горной породы к сопротивлению для её разрушения. Такая форма силовых импульсов и кратковременность их воздействия на горную породу снижает глубину внедрения в нее коронки, формируя волну растяжения, разрушающую буровой инструмент, прежде всего соединения бурильных труб. В связи с этим возникла необходимость в научном обосновании и разработке принципиально нового формирователя силовых импульсов, соответствующих процессу сопротивления горной породы внедрению в нее породоразрушающего инструмента, а также резьбовых соединений бурильных труб, учитывающих волновой характер распространения силовых импульсов по бурильной колонне. Цель: научное обоснование и разработка принципиально нового формирователя силовых импульсов в бурильной колонне, учитывающего характер изменения сопротивления внедрению породоразрушающего инструмента в грунт, и новой конструкции резьбовых соединений бурильных труб, учитывающей волновой характер распространения через них энергии силовых импульсов на забой применительно к бурению пилотной скважины при бестраншейной прокладке трубопроводов.

объекты: технология и техника процесса горизонтально-направленного бурения пилотных скважин с использованием энергии силовых импульсов, распространяющихся по бурильной колонне.

Методы: обобщение и анализ научно-технической информации; методы теоретической и прикладной механики; тензометрирование процессов передачи упругих волн деформаций на стенде, имитирующем искусственные скважины; математическое моделирование работы системы формирования силовых импульсов и процесса распространения их через резьбовые соединения бурильной колонны.

Результаты. Приведен обзор способов бестраншейной прокладки трубопроводов. Определены перспективы совершенствования технологии и техники горизонтально-направленного бурения пилотных скважин как начального этапа технологии бестраншейной прокладки трубопроводов. Предложены технические решения по совершенствованию технологии и техники горизонтально-направленного бурения пилотных скважин, обеспечивающих существенное увеличение механической скорости проходки скважины.

\section{Ключевые слова:}

Горизонтально-направленное бурение, установка, гидравлическая система, колонна бурильных труб, соединение бурильных труб, силовой импульс.

\section{Введение}

Анализ тенденций развития технологий бестраншейной прокладки трубопроводов показал, что к настоящему времени в мире накоплен огромный опыт прокладки трубопроводов и коммуникаций как управляемыми, так и неуправляемыми установками [1-10].
Актуальность и перспективность способа бестраншейной прокладки трубопроводов определяет значительный научный интерес к данному направлению. Так, например, в Институте горного дела Сибирского отделения Российской академии наук разработана классификация способов сооружения скважин, учитывающая специфику про- 
кладки подземных каналов в грунте и способствующая синтезу новых технологий и технических средств $[1,11]$.

Неуправляемый метод основан на горизонтальном прямолинейном внедрении трубопроводов за счет статического или ударного воздействия. Одним из первых и простых бестраншейных технологий стал метод прокола: первоначально представлявший механический способ разрушения, а впоследствии усовершенствованный и использующий энергию струи воды для размыва грунта перед породоразрушающим инструментом $[12,13]$ или другой вариант реализации, - с применением источника продольно-направленных колебаний - вибромолоты [14].

Кроме того, в технологии прокола используют пневмопробойник - самодвижущуюся пневматическую машину ударного действия [15].

Область применения технологии прокола имеет ряд недостатков и ограничений по максимальному диаметру 500 мм и длине до 100 м.

Управляемый метод прокладки трубопроводов бестраншейными технологиями основан на использовании буровых установок горизонтальнонаправленного бурения. Прокладка подземных трубопроводов по технологии горизонтально-направленного бурения выполняется в несколько этапов: бурение пилотной скважины, последовательное её расширение и протягивание трубопровода.

Сооружение скважин в грунте бурением широко используется как в мировой практике подземного строительства, так и в отечественном производстве.

Поиск технических решений (гидроударное бурение; бурение скважин с частичной экскавацией грунта; пневмопробойники для сооружения скважин в грунте; применение пневмомолотов) и исследовательский опыт приводят к выводу, что более перспективным является бурение, сопровождаемое разрушением и удалением значительной части грунта из скважины $[1,7,16]$.

Как правило, установки для механического бурения имеют породоразрушающий инструмент вращательного действия [12]. К недостаткам таких буровых установок можно отнести низкую эффективность работы при встрече с твердыми горными породами или другими труднопреодолимыми препятствиями.

\section{Перспектива развития технологии горизонтально-направленного бурения при бестраншейной прокладке трубопроводов}

В процессе реализации технологии горизонтально-направленного бурения скважин нередко возникают проблемы, когда на планируемой траектории бурения пилотной скважины встречаются включения с высокой твердостью. Поэтому в ряде развитых стран для горизонтально-направленного бурения были созданы установки, оснащенные достаточно мощными гидравлическими ударными механизмами [5, 13], которые формировали в бурильной колонне силовые импульсы, распространяющиеся по ней со скоростью звука к породоразрушающему инструменту и, разрушив встреченное в грунте включение с высокой твердостью, позволяли беспрепятственно продолжать бурение скважины. Но одновременно возникла другая проблема, связанная с резким снижением долговечности резьбовых соединений труб бурильной колонны, поскольку бойки ударных механизмов формировали силовые импульсы с крутым передним фронтом. Такая форма силовых импульсов и кратковременность их воздействия на горную породу снижает глубину внедрения в нее коронки [17]. При этом значительная часть переднего фронта волны деформации сжатия, не встречая достаточного сопротивления в начале процесса внедрения коронки в горную породу, отражается и распространяется обратно по бурильной колонне волной растяжения, которая является основной причиной разрушения резьбовых соединений в бурильной колонне.

В результате возникла необходимость в научном обосновании и разработке принципиально нового формирователя силовых импульсов, соответствующих процессу сопротивления горной породы внедрению в нее породоразрушающего инструмента. Кроме того, следует отметить, что существующие конструкции резьбовых соединений бурильных труб не учитывают волновой характер воздействия распространяющихся по колонне силовых импульсов $[18,19]$. В частности, резьбовое соединение «труба в трубу» всегда имеет изменения поперечного соединения, что вызывает отражения силовых импульсов, а следовательно, существенную потерю их энергии, передаваемой по бурильной колонне к породоразрушающему инструменту. В случае соединения труб муфтами отражения силовых импульсов возникают в результате контактного взаимодействия витков резьбы муфт и бурильных труб. Имея больший диаметр по отношению к соединяемым трубам, муфты сравнительно быстрее изнашиваются при вращении колонны в процессе бурения скважин, что снижает их прочность.

Для решения отмеченных проблем совершенствования технологии и техники горизонтальнонаправленного бурения пилотных скважин как начального этапа бестраншейной прокладки трубопроводов необходимо научное обоснование и разработка как принципиально нового формирователя силовых импульсов в бурильной колонне, учитывающего характер изменения сопротивления внедрению породоразрушающего инструмента в грунт, так и новой конструкции резьбовых соединений бурильных труб, учитывающей волновой характер распространения через них энергии силовых импульсов на забой скважины. 


\section{Гидравлическая система формирования силовых импульсов}

Обзор и анализ технической литературы по вопросам разработки установок горизонтально-направленного бурения показал, что в настоящее время достаточно хорошо разработаны теоретические основы методики их проектирования. Данные разработки способствовали созданию совершенных конструкций машин ударного действия. Вместе с тем стоит отметить, что пневматические ударные механизмы имеют низкий КПД по отношению к гидравлическим или электрическим. Электроударные машины имеют ряд существенных ограничений, из-за которых проблема создания мощных электроударных машин на сегодняшний день не решена в полной мере. Представленное в работе [18] техническое решение по формированию импульсов, направленных на разрушение горной породы, позволяет увеличить КПД буровых установок по сравнению с аналогами. Однако предложенная система имеет несовершенную конструкцию гидроцилиндра, потери давления масла в гидроцилиндре из-за возможности его утечек в сопряжении с поршнем влияют на мощность и КПД установки.

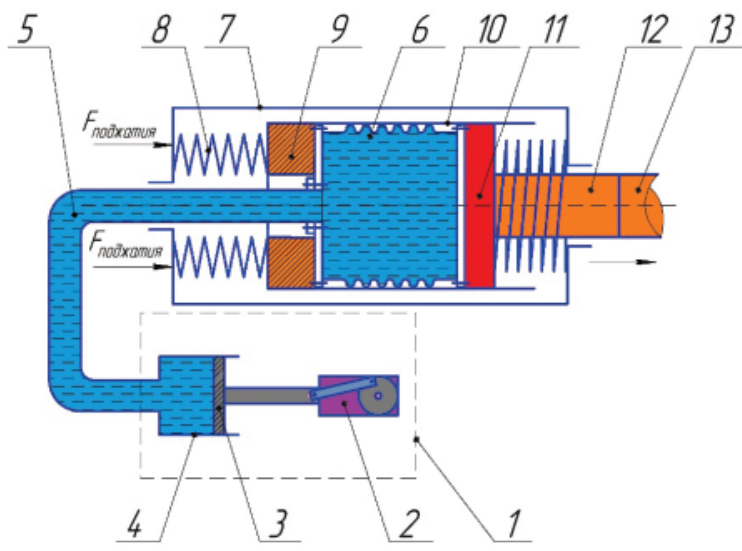

Pис.1. ударный механизл установки ударно-вращательного бу рения: 1 - гидропульсатор; 2 - привод; 3-плунжер; 4 - ги дравлический цилиндр; 5 - упругий элемент; 6 - сильфон; 7 - защитный корпус; 8- пружина; 9 - инериионная масса; 10 - силовой гидроцилиндр; 11 - подпружиненный пор шень; 12 - хвостовик колонны бурильных труб; 13 - колонна бурильных труб

Fig. 1. Percussion mechanism of percussion rotary drilling rigs: 1 is the hammerless hydraulic power pulse generator; 2 is the drive; 3 is the plunger; 4 is the hydraulic cylinder; 5 is the elastic element; 6 is the bellow; 7 is the container housing; 8 is the spring; 9 is the inertial mass; 10 is the hydraulic power cylin der; 11 is the spring-loaded piston; 12 is the shank of the dril string; 13 is the drill string

Разработанная и усовершенствованная авторами конструкция системы формирования силовых импульсов представляет из себя ударный механизм установки ударно-вращательного бурения, содержащий гидравлически соединенные между собой гидропульсатор - 1 с приводом - 2 , плунжер - 3 , расположенный в гидравлическом цилин- дре - 4. Полости гидравлического цилиндра соединены с полостью сильфона - 6. Пружина - 8 в защитном корпусе - 7 опирается на подпружиненную инерционную массу - 9, размещенную на торце силового гидроцилиндра - 10 и соединенного с полостью сильфона - 6. Сильфон - 6 жестко соединен с подпружиненным поршнем - 11, опирающимся на хвостовик - 12 колонны бурильных труб - 13 (рис. 1) [20-23].

Плунжер - 3, приводимый в действие пульсатором, совершает возвратно-поступательные движения в гидравлическом цилиндре, которые, в свою очередь, формируют импульсы давления с плавно нарастающим передним фронтом. Последние приводят к колебаниям жидкости в упругом элементе. Сформированный таким образом силовой гидравлический импульс передается в сильфон - 6 и, воздействуя на подпружиненный поршень - 11 через хвостовик - 12, по бурильной колонне - 13 передается к породоразрушающему инструменту $[18,20,21]$.

Следует отметить, что в данной конструкции заложено автоматическое регулирование силовых импульсов. В процессе бурения в породах слабой крепости амплитуда формируемых силовых импульсов будет небольшой, т. к. на пути породоразрушающего инструмента не будет большого сопротивления породы. Но при появлении на пути породоразрушающего инструмента предметов или горной породы высокой твердости силовой импульс, сформированный плунжерной парой, будет иметь большую амплитуду и обеспечит необходимую мощность для преодоления препятствия.

\section{Решение проблемы обеспечения эффективной передачи энергии силовых импульсов по бурильной колонне}

В процессе ударно-вращательного бурения пилотных скважин малого диаметра соединения бурильных труб нагружены осевым усилием подачи, крутящим моментом и силовыми импульсами. Представление о воздействии сложных силовых нагрузок на резьбовое соединение при проектировании бурильных колонн позволяет повысить долговечность резьбовых соединений [19].

На практике доказано, что поломка резьбовых соединений при бурении ударно-вращательным способом происходит вследствие нагружения несовершенных конструкций резьбовых соединений силовыми импульсами [22]. Последнее приводит к увеличению затрат ресурсов (стали, времени и т. п.), представляет для практики бурения существенную проблему и требует решения путем разработки конструкции соединения труб, учитывающей особенности нагружения соединения в процессе эксплуатации и, как следствие, обладающей повышенной работоспособностью.

При прохождении силовых импульсов по бурильной колонне форма волны деформации изменяется, а энергия частично рассеивается. Обзор научных литературных источников показал, что на- 
дежность работы соединения труб возможно увеличить, снижая долю рассеянной в нем энергии, связанной с трением витков резьбы [22].

На сегодняшний день в технологии горизонтально-направленного бурения пилотных скважин малого диаметра применяют трубы с высаженными концами вовнутрь и резьбовым соединением «труба в трубу» (рис. 2).

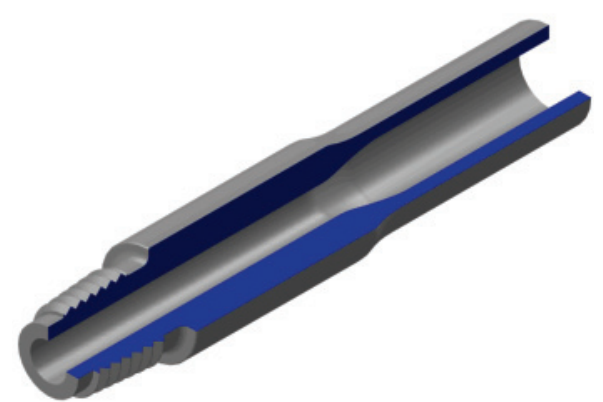

Рис. 2. Бурильная труба с резьбовым соединением «труба в трубу»

Fig. 2. Drill pipe with pipe-to-pipe thread joint

Выполненные авторами [19] теоретические и экспериментальные исследования позволили определить наиболее эффективную конструкцию резьбового соединения бурильных труб [24].

Предложенное на основе этих исследований ниппельное соединение (рис. 3) включает бурильные трубы и ниппель - соединительный элемент, расположенный внутри труб. Трубы имеют внутреннюю круглую цилиндрическую резьбу. Ниппель представляет конструкцию с внешней резьбой, центрирующим буртиком и проточками.

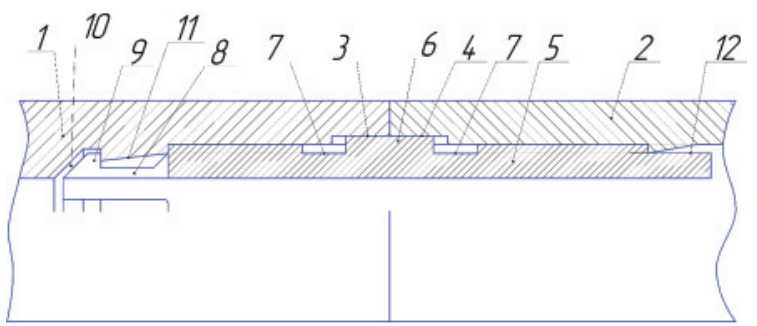

Pис. 3. Ниппельное соединение бурильных труб: 1,2-бурильные трубы; 3, 4- проточки; 5- ниппель; 6 - центрирующий буртик; 7 - кольцевые проточки; 8 - упругие пластины; 9 - буртик со скошенной передней гранью; 10 - кольцевая проточка; 11 - конусная проточка; 12 - льски под ключ

Fig. 3. Nipple joint of drill pipes: 1, 2 are the drill pipes; 3,4 are the faces; 5 is the nipple; 6 is the centralizing collar; 7 are the circular faces; 8 are the elastic plates; 9 is the collar; 10 is the cir cular face; 11 is the tapered face; 12 is the flattened surface

Одним из важных технических решений предлагаемого соединения бурильных труб является наличие устройства для нежесткой фиксации ниппеля в одной из соединяемых труб. Это необходимо при автоматизации процесса развинчивания соединения труб с полностью скрытым в них ниппелем, поскольку без устройства фиксации ниппель может произвольно вывинчиваться одновременно из обеих бурильных труб. Подобное решение реализо- вано посредством упругих пластин, расположенных на дорезьбовой части ниппеля, которые снабжены буртиками со скошенной передней гранью.

Кроме того, следует отметить, что благодаря нежесткой фиксации ниппеля и возможности смещения его относительно соединяемых бурильных труб во время прохождения через соединения силовых импульсов существенно большая часть деформации ниппеля, как показали эксперименты [24], заменяется его смещением относительно бурильных труб, что многократно увеличивает время безотказной работы ниппеля и в целом резьбового соединения труб.

При выборе указанного выше варианта соединений труб в бурильной колонне возникает задача обоснования и расчета рациональных геометрических параметров элементов устройства для нежесткой фиксации ниппеля в бурильной трубе, в частности длины упругих пластин - 8 с буртиком - 9 и их плоских поперечных сечений (рис. 3 ). С этой целью упругую пластину - 8 можно рассматривать как консольную балку, нагруженную на незакрепленном конце сосредоточенной силой, и по заданной величине перемещения буртика - 9 определить изгибающий момент и провести расчет на прочность пластины - 8, предварительно задавая геометрические параметры ее поперечного сечения и механические свойства материала пластины. Следует отметить, что при изгибе предельные упругие перемещения связаны не только со свойствами материала, но и в равной степени с отношением длины балки к размерам ее поперечного сечения в плоскости изгиба, последнее часто вызывает сложности в совместимости результатов предварительно принятых решений.

Для фиксирования одной половины ниппеля в бурильной трубе один конец его с упругими пластинами -8 вворачивается в резьбовую часть труб с проточкой, в которой должен разместиться буртик -9 . При этом буртик будет изгибать пластину с максимальным прогибом, равным высоте резьбы. Для проведения расчетов по выбору рациональных геометрических параметров упругих пластин с буртиком можно принять высоту круглой резьбы равной 1,75 мм, которая использовалась в колонне бурильных труб с ниппельными соединениями [24]. Однако максимальный прогиб пластин - 8 желательно принять с небольшим запасом, т. е. равным 2 мм. Глубину проточки в бурильных трубах принимаем 2,5 мм для размещения в ней буртика с возможностью нежесткой фиксации ниппеля на резьбовом участке бурильной трубы.

Поставленную задачу решаем, составив уравнение упругой линии консольной балки, нагруженной на конце сосредоточенной силой $P$. Примем начало координат $x, y$ в заделке балки. Изгибающий момент в сечении $x$ равен $M=P(l-x)$ (рис. 4). Подставив это выражение в приближенное дифференциальное уравнение упругой линии $y^{\prime \prime}=\frac{M}{E J_{x}}$, 
обеспечивающее определение прогиба $(y)$ с точностью, вполне достаточной для практических расчетов, и, дважды проинтегрировав полученное уравнение, найдем

$$
y=\frac{P}{E J_{z}}\left(l \frac{x^{2}}{2}-\frac{x^{3}}{6}+C x+D\right),
$$

где $C$ и $D$ - постоянные интегрирования, определяемые из граничных условий. При $x=0$ в данном случае $y=0$ и $y^{\prime}=0$, поэтому $C=0$ и $D=0$. Тогда

$$
y=\frac{P}{E J_{z}}\left(l \frac{x^{2}}{2}-\frac{x^{3}}{6}\right) .
$$

Максимальное значение прогиба будет в точке приложения силы $P$, т. е. при $x=l$

$$
y_{\max }=\frac{P l^{3}}{3 E J_{z}} \text {. }
$$

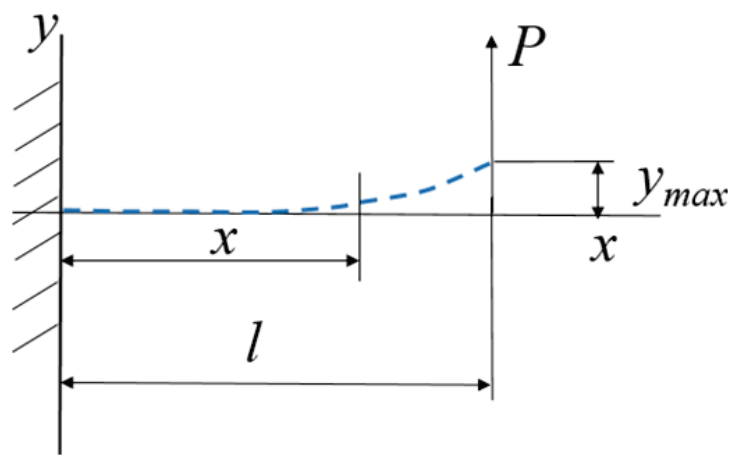

Pис.4 Прогиб консольной балки под действием сосредоточенной сильь

Fig. 4. Hammer beam deflection under the action of concentrated force

Определим усилие $P$, действующее на буртик 9 пластины (рис. 3), используя выражение (1) при заданных значениях:

- $y_{\max }=2 \mathrm{MM} ;$

- длина упругой пластины $l=40 \mathrm{Mm}$;

- нормальный модуль упругости для стали $E=2 \cdot 10^{5}$ МПа;

- момент инерции поперечного прямоугольного сечения упругой пластины

$$
J_{z}=\frac{h^{3} b}{12},
$$

где $b=15$ мм - ширина пластины; $h=2 \mathrm{Mм}$ - толщина пластины.

Тогда из (1)

$$
P=\frac{y_{\max } \cdot 3 E J_{z}}{l^{3}}=\frac{2 \cdot 3 \cdot 2 \cdot 10^{5} \cdot 2^{3} \cdot 15}{40^{3} \cdot 12}=187,5 \mathrm{H} .
$$

Используя полученное значение силы, действующей на буртик - 9 пластины -8 , по известной зависимости

$$
\sigma_{\max }=\frac{M_{\text {изг }}}{W_{z}}=\frac{6 P \cdot l}{h b^{2}}
$$

определяем максимальную величину напряжений в пластине - 8 по изгибающему моменту в заделке пластины и осевому моменту сопротивления поперечного сечения пластины

$$
\sigma_{\max }=\frac{6 P \cdot l}{h b^{2}}=\frac{6 \cdot 187,5 \cdot 40}{15 \cdot 2^{2}}=750 \mathrm{M \Pi а} .
$$

Таким образом, для изготовления ниппеля с устройством фиксации в одной из соединяемых бурильных труб можно использовать хромоникелевые стали, применяемые при изготовлении бурового оборудования, например 40XН, у которой предел текучести $\sigma_{0,2}=785 \mathrm{MПа} \mathrm{[25],} \mathrm{что} \mathrm{ниже} \mathrm{по-}$ лученного расчетного значения максимального напряжения в пластинах. При необходимости упругую зону напряжений можно увеличить за счет повторных нагружений пластин.

Предложенное соединение труб [24] характеризуется следующим:

- ниппель позволяет минимизировать потери энергии при распространении продольной волны деформации;

- волновой процесс приводит к сжатию участков труб и освобождению ниппеля от нормальных напряжений растяжения и деформации сжатия, создаваемых при затяжке соединения;

- фиксация ниппеля в одной из двух труб позволяет обеспечивать автоматизацию свинчивания-развинчивания бурильных труб;

- буртик и проточки повышают долговечность работы резьбового соединения на изгиб;

- расположение ниппеля внутри соединяемых труб сохраняет постоянство наружного диаметра бурильной колонны.

\section{Выводы}

1. Одним из перспективных путей развития технологии и техники горизонтально- направленного бурения пилотных скважин для бестраншейной прокладки коммуникаций является оснащение буровых комплексов ударными узлами, что, в свою очередь, требует совершенствования конструкции бурильной колонны, прежде всего, соединений бурильных труб, позволяющих эффективно, с минимальными потерями энергии передавать силовые импульсы к породоразрушающему инструменту.

2. Выполненные авторами исследования выявили ряд преимуществ ниппельных соединений перед резьбовыми соединениями «труба в трубу» или муфтовыми. Одна из последних конструкций предложенного ниппельного соединения позволяет автоматизировать процесс «свинчивания-развинчивания» благодаря удерживанию ниппеля в одной конкретной трубе, дает возможность его ограниченного перемещения относительно резьбовых участков труб.

3. Основное преимущество соединений бурильных труб с полностью скрытым в них ниппелем связано с процессом радиального расширения и продольной деформации сжатия труб при прохождении силового импульса. Это освобождает ниппель от продольных деформаций растяже- 
ния, снижает контактные напряжения в сопряженных витках резьбы бурильной трубы и ниппеля, в том числе от существенной доли касательных напряжений, поскольку крутящий момент во время прохождения силовых импульсов передается в основном через плотный контакт торцов соединяемых бурильных труб.

4. Предложенная гидравлическая система формирования силовых импульсов является по существу безбойковым ударным механизмом, обладающим высоким коэффициентом полезного действия по сравнению с обычными гидроударниками, в которых значительная часть энергии расходуется на возвратно-поступательные движения бойка в гидроцилиндре, а также на перемещение жидкости по рукавам высокого давления. Как показали экспериментальные иссле-

\section{СПИСОК ЛИТЕРАТУРЫ}

1. Данилов Б.Б. Пути совершенствования технологий и технических средств для бестраншейной прокладки коммуникаций // Физико-технические проблемы разработки полезных ископаемых. - 2007. - № 2. - С. 69-75.

2. Cai L., Polak M.A. A theoretical solution to predict pulling forces in horizontal directional drilling installations // Tunnelling and Underground Space Technology. - 2019. - V. 83. - P. 313-323.

3. Automatic trenchless horizontal directional drilling using quad motors drilling heads / M.A. Kamel, M. Eishafei, A.-W.A. Saif, A.A. Al-Majed // Proc. of $15^{\text {th }}$ International Multi-Conference on Systems, Signals and Devices. - Tunisia-Hammamet, 2018. P. $1172-1177$.

4. Rabiei M., Chang K.P., M. Gelinas, A. Neale Analysis and design of pipes installed via direct PIPE technology // Proc. of Conference: NASTT No-Dig Show. - Palm Springs, CA, March 25-29, 2018. $-11 \mathrm{p}$

5. Tervydis P., Jankuniene R. Horizontal directional drilling pilot bore simulation // Turkish Journal of Electrical Engineering and Computer Sciences. - 2017. - V. 25. - Iss. 4. - P. 3421-3434.

6. Willoughby D. Horizontal Directional Drilling (HDD): Utility and Pipeline Applications (Civil Engineering). $1^{\text {st }}$ ed. - New York: McGraw-Hill Professional, 2005. - $400 \mathrm{p}$.

7. Najafi M. Trenchless Technology Pipeline and Utility Design. Construction and Renewal. - Michigan: McGraw-Hill, 2005. $489 \mathrm{p}$.

8. Pipe Ramming Projects. - Reston: ASCE Journal Publ., 2008. $82 \mathrm{p}$.

9. Stangl G.A., Levings R.B. Horizontal Directional Drilling (HDD) systems for pilot bore drilling in mixed soil conditions and rock // Proc. of $30^{\text {th }}$ International No-Dig Conference and Exhibition. No-Dig Sao Paulo, 2012. - P. 345-366.

10. Danilov B.B. Substation and Selection of Basic Technological Principles for the Evolvement of a New Procedure of the Controlled Horizontal Drilling // Archives of Mining Sciences. - Warsaw: Polish Academy of Sciences, 2008. - P. 205-212

11. Рыбаков А.П. Основы бестраншейных технологий (теория и практика). - М.: ПрессБюро № 1, 2005. - 304 с.

12. Балаховский М.С. На Российском рынке - американская фирма «Vermeer» // Механизация строительства. - 2000. № $10 .-$ C. $2-7$.

13. Червов В.В. Энергия удара пневмомолота с упругим клапаном в камере обратного хода // ФТПРПИ. - 2004. - № 1. C. $80-89$. дования данной системы, можно формировать силовые импульсы с плавно нарастающим передним фронтом и большей чем обычно длительностью, что позволит более рационально использовать их энергию на разрушение грунта. Причем такая система обладает свойством авторегулирования амплитуды формируемых силовых импульсов в зависимости от жесткости разрушаемой среды. С увеличением твердости горных пород амплитуда силовых импульсов будет автоматически резко возрастать.

Таким образом, реализация научно обоснованных технических решений, защищенных патентами РФ, позволяет существенно повысить производительность и надежность работы установок для горизонтально-направленного бурения пилотных скважин.

14. Пневмопробойники / К.С. Гурков, В.В. Климашко, А.Д. Костылев, В.Д. Плавских, Е.П. Русин, Б.Н. Смоляницкий, К.К. Тупицын, Н.П. Чепурной. - Новосибирск: Изд-во ИГД CO PAH, 1990. - $217 \mathrm{c}$.

15. Гилета В.П., Смоляницкий Б.Н. Проходка скважин с частичной экскавацией грунта // Строительные и дорожные машины. - 2001. - № 4. - С. 7-9.

16. Дерюшева В.Н. Модели пневмогидравлического ударного узла с учетом свойств формирователя импульса и нагрузки: автореф ... канд. техн. наук. - Томск, 2009. - 19 с.

17. Novoseltseva M.V., Masson I.A., Pashkov E.N. Investigation of input signal curve effect on formed pulse of hydraulic-powered pulse machine // IOP Conference Series: Materials Science and Engineering. - 2016. - V. 127. - № 1. - P. 74-77.

18. Shadrina A., Saruev L., Vasenin S. The technology improvement and development of the new design-engineering principles of pilot bore directional drilling // IOP Conference Series: Earth and Environmental Science. - 2014. URL: https://doi.org/10.1088/ 1755-1315/43/1/012068 (дата обращения 12.10.2018).

19. Шадрина А.В., Саруев Л.А., Саруев А.Л. Разработка новых соединений труб для бурения опережающих скважин при проходке тоннелей и прокладке в них газонефтепроводов // Нефтяное хозяйство. - 2011. - № 2. - С. 35-36.

20. Ударный узел установки ударно-вращательного бурения: пат. № 159850 Российская Федерация. МПК Е21B 6/00; заявл. 09.06.2015; опубл. 20.02.2016. - Бюл. № 5. - 3 с.

21. Казанцев А.А., Саруев Л.А. Повышение эффективности вращательно-ударного бурения скважин малых диаметров: монография. - Томск: Изд-во Томского политехнического университета, 2011. - 113 с.

22. Ударный узел установки ударно-вращательного бурения: пат. № 79924 Российская Федерация. МПК Е21В 6/04 (2006.01); заявл. 21.07.2008; опубл. 20.01.2009. - Бюл. № 2. - 4 с.

23. Ниппельное соединения буровых штанг: пат. № 157331 Российская Федерация. МПК Е21B 17/42. заявл. 09.06.2015; опубл. 27.11.2015. - Бюл. № 33. - 5 с.

24. Шадрина А.В., Саруев Л.А., Саруев А.Л. Динамические процессы в колонне труб при вращательно-ударном бурении скважин малого диаметра из подземных горных выработок: монография. - Томск: Изд-во Томского политехнического университета, 2009. -175 с.

25. Справочник металлиста. В 5-и т. Т. 2. / под ред. А.Г. Рахштадта, В.А. Брострема. - М.: Машиностроение, 1976. - 720 с.

Поступила 11.02.2019 2. 


\section{Информация об авторах}

Саруев Л.А., доктор технических наук, профессор отделения нефтегазового дела Инженерной школы природных ресурсов Национального исследовательского Томский политехнический университет.

Шадрина A.B., доктор технических наук, доцент отделения нефтегазового дела Инженерной школы природных ресурсов Национального исследовательского Томский политехнический университет.

Саруев А.Л., кандидат технических наук, доцент отделения нефтегазового дела Инженерной школы природных ресурсов Национального исследовательского Томский политехнический университет.

Васенин C.C., машинист технологической установки АО «Газпромнефть - Московский НПЗ».

Пахарев А.В., директор 000 «Геотехновация». 
UDC 621.644

\title{
PROSPECTS FOR DEVELOPMENT OF TECHNOLOGY AND FACILITIES OF PILOT BORES HORIZONTAL DIRECTIONAL DRILLING FOR TRENCHLESS LAYING OF PIPELINES
}

\author{
Lev A. Saruev',
}

saruevla@tpu.ru

Anastasiya V. Shadrina',

avshadrina@rambler.ru

Alexey L. Saruev',

saruev@tpu.ru

Sergey S. Vasenin ${ }^{2}$,

vasenin8@gmail.com

\author{
Aleksandr V. Pakharev ${ }^{3}$, \\ avpaharev@tpu.ru \\ 1 National Research Tomsk Polytechnic University, \\ 30, Lenin Avenue, Tomsk, 634050, Russia. \\ 2 "Gazpromneft - Moskovskiy NPZ», \\ bld. 3, 1, 2 $2^{\text {nd }}$ block, Kapotnya, Moscow, 109429, Russia. \\ ${ }^{3}$ "Geotekhnovatsiya», \\ 4, bld. 5, 79 Gvardeyskaya diviziya street, Tomsk, 634057, Russia.
}

The relevance. In the process of horizontal directional drilling, it is often necessary to overcome solid inclusions or hard rocks, that requires the use of a rational way of their destruction by an impact. However, the existing percussion mechanisms of modern drill rigs form power impulses of irrational form, which do not take into account the properties of the rock to resist destruction. This form of power pulses and the short duration of their impact on the rock reduces the drilling deeper, forming a tensile deformation wave that destroys the drilling tool. Therefore, there was a need for scientific substantiation and development of a conceptually new technique to improve the technology of pilot bores horizontal directional drilling.

The main aim of the research is scientific substantiation and development of a fundamentally new former of power impulses in the drill string, taking into account the behavior penetration resistance into the rock, and new design of thread joints of drill pipes, taking into account the wave nature of the power impulses propagation through them for pilot bores horizontal directional drilling.

Object: facilities of horizontal directional drilling of pilot wells using the energy of power pulses propagating through the drill string. Methods: review and analysis of scientific and technical information; methods of theoretical and applied mechanics; strain measurement of the drill string during elastic deformation waves propagation via a bench simulating artificial bores; mathematic simulation of the power pulses forming system and the process of their propagation through thread joints of the drill string.

Results. The paper introduces the overview of trenchless technology. The authors have identified the prospects for improving the technology of horizontal directional drilling of pilot bores as the initial stage of trenchless pipe laying technology and proposed the techniques to improve the horizontal directional drilling of pilot wells, providing a significant increase in penetration drilling rate.

Key words:

Horizontal directional drilling, drilling rig, hydraulic system, drill string, drill pipe joint, power pulse.

\section{REFERENCES}

1. Danilov B.B. Puti sovershenstvovaniya tekhnologiy i tekhnicheskikh sredstv dlya bestransheynoy prokladki kommunikatsiy [Ways to improve technologies and facilities for trenchless laying of communications]. Journal of Mining Sciences, 2007, no. 2, pp. 69-75.

2. Cai L., Polak M.A. A theoretical solution to predict pulling forces in horizontal directional drilling installations. Tunnelling and Underground Space Technology, 2019, vol. 83, pp. 313-323.

3. Kamel M.A., Eishafei M., Saif A.-W.A., Al-Majed A.A. Automatic trenchless horizontal directional drilling using quad motors drilling heads. Proc. of $15^{\text {th }}$ International Multi-Conference on Systems, Signals and Devices. Tunisia-Hammamet, 2018. pp. 1172-1177.

4. Rabiei M., Chang K.P., Gelinas M., Neale A. Analysis and design of pipes installed via direct pipe technology. Proc. of Conference: NASTT No-Dig Show. At Palm Springs, CA, March 25-29, 2018. $11 \mathrm{p}$.
5. Tervydis P., Jankuniene R. Horizontal directional drilling pilot bore simulation. Turkish Journal of Electrical Engineering and Computer Sciences, 2017, vol. 25, Iss. 4, pp. 3421-3434.

6. Willoughby D. Horizontal Directional Drilling (HDD): Utility and Pipeline Applications (Civil Engineering). $1^{\text {st }}$ ed. New York, McGraw-Hill Professional, 2005. 400 p.

7. Najafi M. Trenchless Technology Pipeline and Utility Design. Construction and Renewal. Michigan, McGraw-Hill, 2005. 489 p.

8. Pipe Ramming Projects. Reston, ASCE Journal Publ., 2008. 82 p.

9. Stangl G.A., Levings R.B. Horizontal Directional Drilling (HDD) systems for pilot bore drilling in mixed soil conditions and rock. Proc. of $30^{\text {th }}$ International No-Dig Conference and Exhibition. No-Dig Sao Paulo, 2012. pp. 345-366.

10. Danilov B.B. Substation and Selection of Basic Technological Principles for the Evolvement of a New Procedure of the Controlled Horizontal Drilling. Archives of Mining Sciences. Warsaw, Polish Academy of Sciences, 2008. pp. 205-212. 
11. Rybakov A.P. Osnovy bestransheynykh tekhnologiy (teoriya $i$ praktika) [Basics of trenchless technologies (theory and practice)]. Moscow, PressByuro № 1 Publ., 2005. 304 p.

12. Balakhovskiy M.S. Na Rossiyskom rynke - amerikanskaya firma "Vermeer» [On the Russian market - the American firm «Vermeer»]. Mekhanizatsiya stroitelstva, 2000, no. 10, pp. 2-7.

13. Chervov V.V. Energiya udara pnevmomolota s uprugim klapanom v kamere obratnogo khoda [Pneumatic hammer impact energy with elastic valve in the recoil stroke chamber]. Journal of $\mathrm{Mi}$ ning Sciences, 2004, no. 1, pp. 80-89.

14. Gurkov K.S., Klimashko V.V., Kostylev A.D., Plavskih V.D., Rusin E.P., Smolyanitsky B.N., Tupitsyn K.K., Chepurnoy N.P. Pneumoproboyniki [Pneumodrifts]. Novosibirsk, IGD SO RAN Publ., 1990. 217 p.

15. Gileta V.P., Smolyanitskiy B.N. Prokhodka skvazhin s chastichnoy ekskavatsiey grunta [Well drilling with partial soil excavation]. Stroitelnye i dorozhnye mashiny, 2001, no. 4, pp. 7-9.

16. Deryusheva V.N. Modeli pnevmogidravlicheskogo udarnogo uzla s uchetom svoysto formirovatelya impulsa i nagruzki. Avtoreferat Kand. nauk [Models of pneumohydraulic percussive mechanism, taking into account the properties of the pulse former and the 10ad. Cand. Diss. Abstract]. Tomsk, 2009. 19 p.

17. Novoseltseva M.V., Masson I.A., Pashkov E.N. Investigation of input signal curve effect on formed pulse of hydraulic-powered pulse machine. IOP Conference Series: Materials Science and En gineering, 2016, vol. 127, no. 1, pp. 74-77.

18. Shadrina A., Saruev L., Vasenin S. The technology improvement and development of the new design-engineering principles of pilot bore directional drilling. IOP Conference Series: Earth and Environmental Science, 2014. Available at: https://doi.org/ 10.1088/1755-1315/43/1/012068 (accessed 12 October 2018).
19. Shadrina, A.V., Saruev, L.A., Saruev, A.L. The new threaded pipe joint for pilot drilling at pipelining. Oil Industry, 2011, no. 2, pp. 36-37. In Rus.

20. Vasenin S.S., Saruev L.A., Kuznetsov I.V. Udarny uzel ustanovki udarno-vrashchatelnogo bureniya [Percussive mechanism of percussion rotary drilling rig]. Patent RF no. 159850, 2016.

21. Kazantsev A.A., Saruev L.A. Povyshenie ehffektivnosti vrashchatelno-udarnogo bureniya skvazhin malykh diametrov: monografiya [Intensification of rotary-percussive drilling of slim holes: monography]. Tomsk, Tomsk Polytechnic University Publ. house, 2011. $113 \mathrm{p}$.

22. Kazantsev A.A., Shadrina A.V., Saruev L.A., Saruev A.L. Udarny uzel ustanovki udarno-vrashchatelnogo bureniya [Percussive mechanism of percussion rotary drilling]. Patent RF no. 79924, 2009.

23. Vasenin S.S., Saruev L.A. Nippelnoe soedinenie burovykh shtang [Nipple joint of drill rods]. Patent RF no. 157331, 2015.

24. Shadrina A.V., Saruev L.A., Saruev A.L. Dinamicheskie protsessy v kolonne trub pri vrashchatelno-udarnom burenii skvazhin malogo diametra iz podzemnykh gornykh vyrabotok: monografiya [Dynamic processes in a drill strings during rotary-percussive drilling of slim holes from underground mining workings: monography]. Tomsk, Tomsk Polytechnic University Publ. house, $2009.175 \mathrm{p}$.

25. Spravochnik metallista [Reference book for metal scientists]. Eds. A.G. Rahshtadt, V.A. Brostrem. Moscow, Mashinostroenie Publ., 1976. Vol. 2, 720 p.

Received: 11 February 2019.

\section{Information about the authors}

Lev A. Saruev, Dr. Sc., professor, National Research Tomsk Polytechnic University.

Anastasiya V. Shadrina, Dr. Sc., associate professor, National Research Tomsk Polytechnic University.

Alexey L. Saruev, Cand. Sc., associate professor, National Research Tomsk Polytechnic University.

Sergey S. Vasenin, engineer, «Gazpromneft - Moskovskiy NPZ».

Aleksandr V.Pakharev, director, "Geotekhnovatsiya». 